\title{
Feasibility Study of Hydroponics as a Home Industry
}

\author{
Azizul Kholis ${ }^{1}$, Indra Maipita ${ }^{1}$, Fitrawaty ${ }^{1}$, Herkules $^{2}$, \\ Gaffar Hafiz Sagala ${ }^{1 *}$, Rangga Restu Prayogo ${ }^{1}$ \\ ${ }^{1}$ Faculty of Economics, Universitas Negeri Medan \\ ${ }^{2}$ Faculty of Mathematics and Natural Science \\ "Corresponding author. Email: hafizsagala@unimed.ac.id
}

\begin{abstract}
This study aims to analyze the feasibility of a hydroponic business on a home industry scale. This research tries to respond to the rising hydroponic farming system, which allows it to be applied as an alternative to a home business. However, this development is not yet optimal for new entrepreneurs because the investment value is relatively high. Meanwhile, a business feasibility study is needed to justify that the high investment value is commensurate with the profitability generated from the hydroponic business. The feasibility study results indicate that the hydroponic business with a home industry scale has excellent profitability. However, despite having a good return ratio, the income generated is relatively small as the primary income. Therefore, there is a need for continuous development in the hydroponic business to increase the production capacity of the hydroponic system. Furthermore, further studies are needed regarding market acceptance of hydroponic products to ensure the company's sustainability. Nevertheless, this study has provided empirical evidence that the hydroponic industry has potential and financial benefits as an alternative to starting a home-based business.
\end{abstract}

\section{Keywords: Hydroponics, Home Industry, Feasibility Study}

\section{INTRODUCTION}

Hydroponics is water-mediated agriculture which in the last decade has become an alternative to agricultural systems with limited land, especially in urban areas [1,2]. This farming system is believed to not only have land efficiency but is also an environmentally friendly agricultural system and can become an alternative to food security [3,4]. Furthermore, food security can be obtained from direct hydroponic crops and indirectly from the sale of hydroponic products in the agricultural business. Therefore, hydroponics can be an attractive alternative to starting a home business in the farming sector with such flexibility and benefits.

Hydroponic farming has several characteristics that are suitable for the home industry in urban areas. With limited land, hydroponics can be applied with a vertical system to allow good productivity. In addition, hydroponic farming has a short cropping cycle and allows for various types of plants to be planted in one growing medium [5]. Thus, hydroponic farming has good flexibility so that hydroponic entrepreneurs have the flexibility to adjust their products to market expectations.

Hydroponic farming as an alternative business has attracted attention in various countries. Hydroponic agriculture is attracting attention both as an alternative to food security and home businesses to achieve community economic resilience [6,7]. On the other hand, market demand for vegetable products has also led to local and environmentally friendly products $[3,4,7]$. Therefore, the opportunity of hydroponic business is increasingly interesting as an alternative to the home industry. However, the response of prospective entrepreneurs to start a hydroponic business is still weak due to concerns about the high investment value [8]. Nevertheless, if the return from the investment has good profitability, then the hydroponic business deserves to be accepted as an alternative home industry for new entrepreneurs. 
On the other hand, research related to hydroponic business opportunities has not been widely carried out. Meanwhile, research about hydroponics is still dominated by studies that examine aspects of agricultural cultivation. Therefore, this study aims to analyze the feasibility of a hydroponic business on a home-based business scale. The feasibility study findings will provide an overview to prospective hydroponic entrepreneurs regarding the profitability of the hydroponic business and how to optimize it so that it is worthy of consideration as a side or primary source of income. In addition, this study provides empirical evidence that the hydroponic business has excellent potential and financial appeal as an alternative to starting a home-scale business.

\section{THEORETICAL FRAMEWORK}

The intention of an entrepreneur in starting a business ideally starts from the opportunity for benefits to be obtained from a business, especially economic benefits $[9,10]$. Generally, this economic benefits analysis is compared with the costs incurred in a business investment [11]. The study of these costs and benefits is commonly also referred to as a business feasibility study. Entrepreneurs carry out a business feasibility study to get an objective view of the business they will run, which will lead to an investment decision or not [10]. This study is increasingly crucial in hydroponic investment decisions because hydroponics is known as a system that requires a high investment value [8]. Therefore, this system is often doubted by new entrepreneurs and is not an alternative in great demand. Furthermore, hydroponic farming is interested more for environmental reasons, food security, and a flexible alternative to modern agriculture than for reasons of economic benefits [12]. Therefore, the hydroponic business feasibility study will provide additional considerations in making business investment decisions in this agricultural sector.

Feasibility studies on the financial aspect are usually conducted after the analysis of other elements has been completed, such as market segmentation, organizational, legal aspects, and personnel [11]. However, financial evaluation is usually the most crucial aspect in determining business investment decisions. Analysis of this aspect is calculated by estimating the number of funds needed, both for investment procurement and working capital needs. In addition, it is also analyzed how the most profitable financing structure. From a financial or financial perspective, a project is feasible if it can provide benefits and meet its financial obligations if the investment funds are obtained from a third party.

There are several alternatives to conduct investment feasibility studies [9-11]. Each generally shows how the invested funds are performing in generating the expected economic benefits. For example, the analysis results can be the income ratio to costs and production targets needed to achieve an inevitable return on capital. Here are some alternatives used in investment feasibility studies.

1. Net Present Value (NPV). NPV calculates the difference between the present value of the investment and the present value of net cash receipts (operational or terminal cash - flow) in the future. If the current value / NPV is greater than 0 , then the project can be profitable, and vice versa.

2. Internal Rate of Return (IRR). IRR is the interest rate that equates to the present value of cash outflows and the present value of cash inflows.

3. Payback Period (PP). $\mathrm{PP}$ is the amount required to recover or cover the initial investment cost with a specific rate of return. The calculation is based on cash flow, both annual and salvage value.

4. Break-Even Point (BEP). BEP is the point of return on investment in units. With BEP, investors can review how much the business will get a return on capital on the production unit.

Return on investment (ROI). ROI is the ratio of return on investment made by comparing the investment value with income. This ratio will show how income performs in terms of investment returns over the annual period and the estimation period of the productive period of the tools invested.

\section{METHOD}

The feasibility study was conducted to review whether investing in the hydroponic business has profitability from a financial point of view and to what extent this profitability is worth considering for individuals who will start a new business. The investment feasibility study reviews the NPV, IRR, $\mathrm{PP}, \mathrm{BEP}$, and ROI. These ratios are very commonly used and are considered reliable for examining investment feasibility. The discount value used is $6 \%$ referring to the interest rate of Bank Indonesia. Furthermore, the researcher uses a discount value of $302 \%$ because the NPV is negative or close to 1 .

Furthermore, the feasibility study simulation uses three general commodities and is easy to apply to hydroponic cultivation but has good market demand, 
namely 1) Lettuce, 2) Kale, and 3) Mustard. Therefore, those three commodities were analyzed for feasibility with the assumed investment value, including 1) Hydroponic construction with a business-scale greenhouse with a capacity of 1,000 stems or seedling points; 2) Seedlings; and 3) Nutrient Fertilizer. Hydroponic devices are assumed to last for five productive years. In that range of years, a number of plants that are sown will produce different production capacities. The value of production capacity is calculated based on the trials carried out and theoretical estimates that generally occur in hydroponic cultivation.

Before calculating the simulation, it is necessary to determine the estimated value of the investment allocated to build business-scale hydroponic infrastructure. The calculation of the investment value is carried out by interviewing hydroponic entrepreneurs and recalibrating with various hydroponic construction adjustments for the home industry scale according to the criteria above. based on the results of the calculation of the investment value with these criteria is equivalent to Rp. 32,470,000.-After the estimated investment value is obtained, a simulation calculation of the ratio of NPV, IRR, PP, $\mathrm{BEP}$, and ROI is carried out on Lettuce, Kale, and Mustard commodities. The estimated price is calculated in units referring to the prevailing market prices for the three hydroponic vegetable products.

\section{RESULT}

The results of the feasibility study are observable in table 1 below. The results of the feasibility study show that the hydroponic business has an excellent profitability ratio. With NPV Value > Rp. 95,000,000,- for the three commodities IRR >295\% and payback period around \pm 1 year. This condition shows that the investment value invested in hydroponic infrastructure can be returned within one year and generate returns three to four times as long as the hydroponic equipment's productive life.

This condition is also observable from the fiveyear ROI number, estimated at $362 \%$ for lettuce, $476 \%$ for kale, and $477 \%$ for mustard. Each commodity has a BEP in a significantly different unit. However, when viewed from the production capacity of each commodity, it also has a significantly different range. Therefore, it can be reviewed in units of time in the payback period for more accurate reference. However, the unit reference in the BEP is essential to maintain the stability of the production capacity of each commodity so that the investment return target is achieved according to the plan. Furthermore, the annual ROI shows that the profit earned in one year has been able to return $75 \%$ of the investment value in lettuce commodities, while $95 \%$ for Kale and Mustard commodities.

From the ratio figures obtained, the hydroponic business investment is very promising and has excellent profitability. However, this ratio does not necessarily describe the optimal value of income obtained by hydroponic cultivators. If viewed from the value of income in monetary units, a hydroponic entrepreneur can get Rp. 30,000,000,- per year for commodity lettuce, Rp. 37.400.000,- for Kale commodity, and Rp. 37.500.000- for Mustard commodity. However, when the profit earned is calculated, after deducting the investment depreciation value, the annual profit is only Rp. $23,506,000$ or $\mathrm{Rp}$. $1,958,833$ per month for lettuce, Rp. 30,906,000, - per year or Rp. 2,575,500,- per month for Kale commodity, and Rp. 31.006.000,- per year or Rp. 2,583,833, - per month for Mustard commodity. This figure is indeed not a superior number for the main business that supports the needs of daily life. Therefore, hydroponic entrepreneurs must be cautious in maintaining the consistency of vegetable production and timely harvesting. In addition, hydroponic businesses must periodically increase hydroponic production capacity by expanding or enlarging hydroponic growing media devices.

Tabel 1. Feasibility Study Simulation of Hydroponic Business Investment

\begin{tabular}{|c|c|c|c|c|}
\hline \multirow{2}{*}{ No } & \multirow{2}{*}{ Variable } & \multicolumn{3}{|c|}{ Commodity } \\
\hline & & Lettuce & Kale & Mustard \\
\hline 1 & Production Capacity & 300 unit & 1000 unit & 500 unit \\
\hline 2 & Harvest Number Per Year & 5 times & 4 times & 5 times \\
\hline 3 & Price per Unit/Package & Rp. 20.000,- & Rp. 9350,- & Rp. 25.000,- \\
\hline 4 & Revenue Estimation (annually) & Rp. $30.000 .000,-$ & Rp. $37.400 .000,-$ & Rp. 37.500 .000 ,- \\
\hline 5 & Profit Estimation (annually) & Rp. 23.506.000,- & Rp. 30.906.000,- & Rp. 31.006.000,- \\
\hline 6 & Investment & Rp. $32.470 .000,-$ & Rp. 32.470 .000 ,- & Rp. 32.470.000,- \\
\hline 7 & Hydroponic Productive Period & & 5 years & \\
\hline 8 & Disconto rate & \multicolumn{3}{|c|}{$6 \%$ and $302 \%$ (for negative NPV or equal to 0 ) } \\
\hline 9 & NPV & Rp. 95.599.027,- & Rp. 127.189.387 & Rp. 127.616.283 \\
\hline 10 & IRR & $296 \%$ & $316 \%$ & $316 \%$ \\
\hline 11 & PP & 1,08 & 0,87 & 0,86 \\
\hline 12 & BEP & 1624 Unit & 3473 Unit & 2165 Unit \\
\hline 13 & ROI (five year period) & $362 \%$ & $476 \%$ & $477 \%$ \\
\hline 14 & ROI (annually) & $72 \%$ & $95 \%$ & $95 \%$ \\
\hline
\end{tabular}

\section{CONCLUSION}

The results of this study reveal that home-scale hydroponic construction can be applied as a cottage industry with attractive profitability estimates. Based on the feasibility study results, the hydroponic business has an excellent return on investment ratio. However, entrepreneurs must be careful with the 
actual return value distributed into profit per month because the profit per month does not necessarily meet business expectations from hydroponic investment. However, with sustainable development planning followed by overall market development, a hydroponic business with a large planting scale and investment will generate even greater profits. Therefore, the hydroponic investment must be followed by sustainable and planned development.

In addition, the increasing productivity of hydroponic agriculture will simultaneously demand good market absorption. Therefore, in addition to increasing the productivity of agricultural products, hydroponic businesses must also prepare a good product marketing strategy. Further research can examine aspects of hydroponic products' market acceptance to formulate appropriate marketing strategies for hydroponic products.

\section{ACKNOWLEDGMENTS}

This study was funded by the Internal Grant (PNBP) of Universitas Negeri Medan, Indonesia.

\section{REFERENCES}

[1] Sharma, N., Acharya, S., Kumar, K., Singh, N., \& Chaurasia, O. P. Hydroponics as an advanced technique for vegetable production: An overview. Journal of Soil and Water Conservation. 17 (4), 2018, pp 364-371.

[2] Sihombing, P., Karina, N. A., Tarigan, J. T., \& Syarif, M. I. Automated hydroponics nutrition plants systems using arduino uno microcontroller based on android. In Journal of Physics: Conference Series. Vol. 978, No. 1. IOP Publishing. 2018.

[3] Balqiah, T. E., Pardyanto, A., Astuti, R. D., \& Mukhtar, S. Understanding how to increase hydroponic attractiveness: Economic and ecological benefit. In E3S Web of Conferences . Vol. 211. EDP Sciences. 2020.

[4] Naz, F., Oláh, J., Vasile, D., \& Magda, R. Green Purchase Behavior of University Students in Hungary: An Empirical Study. Sustainability. 12 (23), 10077, 2020.

[5] Bouchard, M., \& Dion, C. B. Growers and facilitators: probing the role of entrepreneurs in the development of the cannabis cultivation industry. Journal of Small Business \& Entrepreneurship. 22 (1), 2009, pp 25-37.

[6] Sisodia, G. S., Alshamsi, R., \& Sergi, B. S.
Business valuation strategy for new hydroponic farm development-a proposal towards sustainable agriculture development in United Arab Emirates. British Food Journal. 2020.

[7] Specht, K., Siebert, R., \& Thomaier, S. Perception and acceptance of agricultural production in and on urban buildings (ZFarming): a qualitative study from Berlin, Germany. Agriculture and Human Values, 33 (4), 2016, pp 753-769.

[8] Pascual, J. A., Ceglie, F., Tuzel, Y., Koller, M., Koren, A., Hitchings, R., \& Tittarelli, F. Organic substrate for transplant production in organic nurseries. A review. Agronomy for Sustainable Development. 38 (3), 2018, pp 1-23.

[9] Pinson, L. Anatomy of a Business Plan: A Stepby-step Guide to Building the Business and Securing Your Company's Future. Aka associates. 2008.

[10] Sulastri, Lilis. Studi Kelayakan Bisnis, Jakarta: LGM-LaGood's Publishing. 2016.

[11] Purwana, D., \& Hidayat, N. Studi Kelayakan Bisnis. Depok: Rajagrafindo Persada. 2016.

[12] Blok, V., Thijssen, S., \& Pascucci, S. Understanding management practices in business incubators: Empirical evidence of the factors impacting the incubation process. International Journal of Innovation and Technology Management. 14 (04), 2017, p 1750023. 